\title{
Analisis Perbandingan Kinerja Keuangan Perusahaan Sebelum dan Sesudah Merger dan Akuisisi
}

\author{
Nur Fathun Ni'mah* \\ L.M Samryn** \\ *Universitas Jayabaya \\ **Universitas Jayabaya
}

\section{ARTICLE INFO}

Keywords:

Acquisitions, merger, financial performance, public company

Corresponding Author: lmsamryn@yahoo.com
Manajerial

Volume 9 Nomor 1

Mei-Oktober 2015

ISSN. 1907- 4832

\section{ABSTRACT}

This study aims to analyze the differences in firm performance before and after mergers and acquisitions on corporate merger and acquisition activity. Corporate performance is measured by using financial ratio: Net Profit Margin (NPM), Return On investment (ROI), Return On Equity (ROE), Debt Ratio, Total Assets Turnover (TATO), Current Ratio (CR) and Earning Per Share (EPS). Quantitative method is used in this research, take the data of public company which had conducted mergers and acquisitions in Indonesia Stock Exchange (IDX) and announce its activity in the period 2007-2011, and analyzed using Wilcoxon signed ranks test and Manova are used to answer hypothesis. The results from this research show that study in 7 financial ratio, NPM, ROI, ROE, EPS, TATO, CR and Debt. On the acquire does not show significant differences in the comparison before and after the acquisition. But the companies that have merged ROI ratios, EPS and Debt there are significant differences before and after the merger.

Penelitian ini bertujuan untuk menganalisis perbedaan pada kinerja perusahaan sebelum dan sesudah merger dan akuisisi pada perusahaan yang melakukan aktivitas merger dan akuisisi. Kinerja perusahaan diukur dengan menggunakan rasio keuangan: Laba Bersih Margin (NPM), Return On investasi (ROI), Return On Equity (ROE), Debt Rasio, Perputaran Total Aktiva (TATO), Rasio Lancar (CR) dan Produktif per Saham (EPS). Metode kuantitatif digunakan dalam penelitian ini mengambil data dari perusahaan publik yang telah melakukan merger dan akuisisi di Bursa Efek Indonesia (BEI) dan mengumumkan kegiatannya pada periode 2007-2011, dan dianalisis dengan menggunakan Wilcoxon signed tes dan Manova digunakan untuk menjawab hipotesis. Hasil dari penelitian ini menunjukkan bahwa studi dalam 7 rasio keuangan, NPM, ROI, ROE, EPS, TATO, CR dan Debt. Pada pengakuisisi tidak menunjukkan perbedaan yang signifikan dibandingkan sebelum dan sesudah akuisisi. Tapi perusahaan yang telah bergabung rasio ROI, EPS dan Debt Rasio terdapat perbedaan yang signifikan sebelum dan sesudah merger. 


\section{Pendahuluan}

Merger dan akuisisi (M \& A) merupakan fenomena bisnis yang penting (Yu, 2013), sebagaimana dibuktikan oleh volume besar dan meningkatnya kegiatan $\mathrm{M}$ \& A selama bertahun-tahun belakangan ini. Dalam ekonomi kapitalis fenomena M \& A perusahaan merupakan inheren dalam lingkungan yang kompetitif dan terkait dengan pengembangan pasar modal, khususnya yang berkaitan dengan pembiayaan perusahaan (Monteiro, et al., 2014).

M \& A bukanlah terminologi yang sama tetapi sering digunakan secara bergantian. Akuisisi merupakan satu organisasi yang membeli sebagian atau seluruh organisasi lain. Sementara merger adalah pembentukan dua atau lebih dari dua organisasi menjadi satu (Alao 2010). Merger adalah kegiatan legal di mana dua atau lebih organisasi menggabungkan dan hanya satu perusahaan yang bertahan sebagai badan hukum (Horne dan John 2004). Menurut Durga dan Kumar (2013), merger dan akuisisi sebagai kegiatan yang melibatkan pengambilalihan, restrukturisasi perusahaan, atau kontrol perusahaan yang berubah dalam struktur kepemilikan perusahaan.

Seorang Manajer dalam M \& A harus memperhitungkan kinerja dari perusahaan yang akan diakuisisinya. Hal ini dikarenakan pada kinerja perusahaan dapat menilai pantas tidaknya calon perusahaan yang diakuisisi. Perhitungan kinerja tersebut dilakukan dengan melihat rasio-rasio keuangan. Moin (2010) mengatakan bahwa perhitungan tersebut dapat menggunakan return on assets dan return on equity dalam perhitungan rasio profitabilitas, perhitungan rasio likuiditas dengan current ratio, rasio aktivitas dengan menggunakan total asset turn over serta rasio pasar menggunakan earning per share. $\mathrm{x}$

Dalam penelitiannya Dyaksa (2006) menunjukan adanya perbedaan yang signifikan untuk rasio keuangan EPS, NPM, ROE, dan ROA untuk pengujian 1 tahun sebelum dan 1 tahun setelah merger dan akuisisi; rasio keuangan ROE untuk pengujian 1 tahun sebelum dan 2 tahun setelah merger dan akuisisi. sementara Sarah dan Maksum (2009) melakukan penelitian yang menyatakan pada perusahaan pengakuisisi tidak ada perbedaan kinerja keuangan pada rasio likuiditas, aktivitas, leverage dan profitabilitas. Namun, pada perusahaan diakuisisi terdapat perbedaan yang signifikan pada rasio likuiditas dan aktivitas. Hasil negatif juga dikemukakan oleh Payamta dan Setiawan (2004) dan Widjanarko (2006) yang meneliti kinerja keuangan perusahaan yang melakukan merger dan akuisisi dari rasio-rasio ke- uangan. Dari hasil penelitiannya menunjukkan rasio-rasio keuangan dua tahun sebelum dan sesudah peristiwa merger dan akuisisi tidak mengalami perubahan yang signifikan.

Beams dan Yusuf (2000) menyatakan bahwa merger terjadi ketika sebuah perusahaan mengambil alih semua operasi dari entitas usaha lain dan entitas yang diambil alih tersebut dibubarkan. Jadi, setelah merger perusahaan yang diambil alih dibubarkan, sedangkan perusahaan yang mengambil alih tetap beroperasi secara hukum sebagai satu badan usaha dan melanjutkan kegiatan perusahaan yang diambil alih. Baridwan (1992) dalam Hamid (1998) menyatakan bahwa merger terjadi bila suatu perusahaan mengeluarkan saham untuk ditukarkan dengan seluruh saham biasa perusahaan lainnya. Pemegang saham perusahaan yang diambil alih ini menjadi pemegang saham perusahaan yang mengambil alih, dan perusahaan yang diambil alih tidak lagi merupakan perusahaan yang berdiri sendiri, tetapi menjadi bagian dari perusahaan yang mengambil alih

Pihak yang menerima pengalihan dinamakan surviving firm. Sementara itu perusahaan yang berhenti dan bubar setelah terjadinya merger dinamakan merged firm (Kurniawan, 2015). Surviving firm dengan sendirinya akan memiliki ukuran yang semakin besar karena seluruh asset dan kewajiban dari merged firm dialihkan kepada surviving firm. Perusahaan yang dimerger akan menanggalkan status hukumnya sebagai entitas yang terpisah dan setelah merger statusnya berubah menjadi bagian (unit bisnis) di bawah surviving firm. Dengan demikian, merged firm tidak dapat bertindak hukum atas namanya sendiri.

Dalam Peraturan Pemerintah Republik Indonesia No. 27 Tahun 1988 mendefinisikan merger adalah perbuatan hukum yang dilakukan oleh satu perseroan atau lebih untuk menggabungkan diri dengan perseroan lain yang telah ada dan selanjutnya perseroan yang menggabungkan diri menjadi bubar. Ikatan Akuntan Indonesia memberikan definisi berdasarkan perspektif akuntansi bahwa merger adalah salah satu metode penyatuan usaha (business combination). Penyatuan usaha itu sendiri didefinisikan sebagai penyatuan dua atau lebih perusahaan yang terpisah lain atau memperoleh kendali atas aktiva dan operasi perusahaan lain.

Akuisisi mempunyai makna membeli atau mendapatkan sesuatu atau obyek untuk ditambahkan pada sesuatu atau obyek yang telah dimiliki sebelumnya. Dalam terminologi bisnis akuisisi dapat diartikan 
sebagai pengambilalihan kepemilikan atau pengendalian atas saham atau aset suatu perusahaan oleh perusahaan lain, dan dalam peristiwa baik perusahaan pengambilalih atau yang diambil alih tetap eksis sebagai badan hukum yang terpisah (Moin, 2004). Sedangkan Hit (2002) menyatakan bahwa akuisisi yaitu memperoleh atau membeli perusahaan lain dengan cara membeli sebagian besar saham dari perusahaan sasaran. Definisi lainnya menurut Beam (1996) dalam (Utami, 2013) bahwa akuisisi merupakan penggabungan usaha suatu perusahaan ketika memperoleh pengendalian operasi atas fasilitas produktif entitas lain dengan memiliki sejumlah besar (mayoritas) saham yang mempunyai hak suara.

Akuisisi adalah penguasaan sebagian saham dari perusahaan subsidiary, melalui pembelian saham hak suara perusahaan subsidiary, dalam jumlah material (lebih dari 50\%). Pada Pemerintah Republik Indonesia No.27 tahun 1998 tentang penggabungan, peleburan dan pengambilalihan Perseroan Terbatas mendefinisikan akuisisi adalah perbuatan hukum yang dilakukan oleh badan hukum atau perseorangan untuk mengambil alih baik seluruh atau sebagian besar saham perseroan yang dapat meng- akibatkan beralihnya pengendalian terhadap perseroan tersebut.

\section{Metodologi Penelitian}

Penelitian ini dilakukan pada kantor BEI (Bursa Efek Indonesia) yang berlokasi Jl. Jend. Sudirman Kav. 52-5, Jakarta Selatan 12190. Sesuai dengan bidang yang diteliti, maka penelitian ini pada unit of annalistic yang diperoleh dari bagian Publikasi Laporan Keuangan Perusahaan. Penelitian dilaksanakan dalam kurun waktu kurang lebih 3 bulan yang di awali penyusunan proposal penelitian untuk diajukan kepada perusahaan setelah itu selama 2 minggu diantaranya merupakan proses pengumpulan data ditempat penelitian sedangkan sisanya merupakan masa penyusunan pelaporan.

Nazir (2005) mengemukakan bahwa sampel adalah bagian dari populasi. Sedangkan menurut Sugiyono (2007) sampel adalah bagian dari jumlah dan karakteristik yang dimiliki oleh populasi. Dalam penelitian ini sampel yang digunakan sebanyak 6 perusahaan. Diantaranya 3 perusahaan melakukan aktivitas merger dan 3 perusahaan melakukan aktivitas akuisisi.

Tabel 1 Daftar Perusahaan Akuisi

\begin{tabular}{lll}
\hline $\begin{array}{l}\text { Nama } \\
\text { Perusahaan }\end{array}$ & $\begin{array}{l}\text { Nama Perusahaan } \\
\text { yang di Akuisisi }\end{array}$ & $\begin{array}{l}\text { Tanggal } \\
\text { Akuisisi }\end{array}$ \\
\hline $\begin{array}{l}\text { PT Bank Rabobank } \\
\text { Internasional Indonesia }\end{array}$ & $\begin{array}{l}\text { PT Bank Haga dan } \\
\text { PT Bank Hagakita }\end{array}$ & 24 Juli 2008 \\
\hline Bank of India Indonesia & Bank Swadesi & Tahun 2007 \\
\hline Bank Victoria International & Bank Swaguna & 07 Sept. 2007 \\
\hline \multicolumn{1}{c}{ Sumber: BEI, Indonesian Capital Market Directory } &
\end{tabular}

Tabel 2 Daftar Perusahaan Merger

\begin{tabular}{lll}
\hline $\begin{array}{l}\text { Nama } \\
\text { Perusahaan }\end{array}$ & $\begin{array}{l}\text { Nama Perusahaan } \\
\text { yang di Merger }\end{array}$ & Tanggal Merger \\
\hline PT. BANK UOB Indonesia & PT. BANK UOB Buana & 10 Juni 2010 \\
\hline Bank OCBC NISP & Bank OCBC & 1 Januari 2011 \\
\hline $\begin{array}{l}\text { Bank Windu Kentjana } \\
\text { International }\end{array}$ & $\begin{array}{l}\text { Bank Multicor dan } \\
\text { Bank Windu Kentjana }\end{array}$ & 10 Desember 2007 \\
\hline
\end{tabular}

Sumber: BEI, Indonesian Capital Market Directory

Perusahaan-perusahan yang diambil untuk menjadi sampel dalam penelitian ini ialah perusahan-perusahan dalam bidang perbankan yang melakukan akuisi dan merger pada tahun 2007 sampai dengan 2011. Dalam penelitian ini menggunakan jenis data kuantitatif, penulis menggunakan sumber data primer dan data sekunder. Data primer yaitu data yang diperoleh secara langsung dari perusahaan. Data tersebut diperoleh dengan mewawancarai pimpin- an yang berwenang. Data yang bisa didapatkan dari data primer ini berupa sejarah perusahaan dan stuktur organisasi. Data sekunder dalam penelitian ini ialah laporan keuangan perusahan yang diambil dari BEI (Bursa Efek Indonesia) atau Indonesian Capital Market Directory (ICMD) tahun 2004 -2010.

Teknik analisis data, pada dasarnya variabel dalam penelitian ini adalah kinerja keuangan. Secara spe- 
sifik, kinerja keuangan disini difokuskan terhadap kinerja keuangan perusahaan yang melakukan merger dan akuisisi (Munawir, 2001). Kinerja keuangan perusahaan diukur dengan indikator rasio keuangan, yaitu: (1) Rasio Profitabilitas; a. Net Profit Margin b. Return on Investment c. Return on Equity; (2) Rasio pasar yang digunakan dalam penelitian ini adalah Earning Per Share (EPS); (3) Rasio aktivitas yang digunakan dalam penelitian ini adalah Total Assets Turn Over (TATO); (4) Rasio likuiditas yang digunakan dalam penelitian ini adalah Current Ratio (CR). (5) Rasio Solvabilitas; variabel solvabilitas yang digunakan dalam penelitian ini yaitu Debt Ratio, setelah mendapatkan rasio-rasio tersebut teknik analisis data yang digunakan ialah statistik deskriptif memberikan gambaran atau deskriptif suatu data yang dilihat dari rata-rata dan standar deviasi.

\section{Hasil Dan Pembahasan}

Pada tabel 3 terlihat bahwa hasil penelitian yang diperoleh net profit margin menunjukan pada perusahaan Bank UOB Indonesia mengalami penurunan yaitu sebelum merger sebesar 100,30\% menjadi sesudah merger $98.46 \%$ lain halnya dengan perusahaan yang lain menunjukan peningkatan yaitu pada perusahaan Bank OCBC NISP sebelum akuisisi sebesar 55\% menjadi sesudah akuisisi $76 \%$, sama hal dengan perusahaan Bank OCBC NISP, perusahaan Bank Windu Kentjana International juga menunjukan peningkatan dari sebelum akuisisi 5\% menjadi sesudah akuisisi14\% hal ini menunjukan bahwa perusahaan yang melakukan merger menghasilkan pendapatan yang meningkat sebanding dengan penurunan biaya.

Tabel 3. Net Profit Margin Perusahaan sebelum dan sesudah Merger (dalam jutaan rupiah)

\begin{tabular}{lrrrr}
\hline Perusahaan & \multicolumn{2}{c}{ Sebelum } & \multicolumn{2}{c}{ Sesudah } \\
\hline PT Bank UOB & $1,013,000.00$ & $100.30 \%$ & $1,154,000.00$ & $98.46 \%$ \\
Indonesia & $1,010,000.00$ & & $1,172,000.00$ & \\
& $418,662.00$ & $55.42 \%$ & $752,654.00$ & $75.82 \%$ \\
Bank OCBC NISP & $755,381.00$ & & $992,692.00$ & \\
& $4,882.00$ & $5.22 \%$ & $3,651.00$ & $13.75 \%$ \\
Bank Windu Kentjana & $93,478.00$ & & $26,587.00$ & \\
International & & $\mathbf{5 3 . 6 5 \%}$ & & $\mathbf{6 2 . 6 7 \%}$ \\
\hline Rata-Rata & & & &
\end{tabular}

Sumber : Data Primer yang diolah

Dari data primer yang diolah pada tabel 4 diperoleh Return On Invesment pada perusahaan Bank UOB Indonesia mengalami penurunan yaitu sebelum merger sebesar 3,03\% menjadi sesudah merger 3.01\% lain halnya dengan perusahaan yang lain yaitu Bank OCBC NISP dan Bank Windu Kentjana Internatio- nal cenderung meningkat yaitu Sebelum $0.83 \%$ dan $0.24 \%$ menjadi sesudah merger $1.26 \%$ dan $1.74 \%$. Hal ini menunjukan bahwa perusahaan yang melakukan merger memberi dampak positif pada rasio Retun On Invesment.

Tabel 4. Return On Invesment Perusahaan sebelum dan sesudah Merger (dalam jutaan rupiah)

\begin{tabular}{lrrrr}
\hline Perusahaan & Sebelum & \multicolumn{2}{c}{ Sesudah } \\
\hline PT Bank UOB & $1,013,000.00$ & $3.03 \%$ & $1,154,000.00$ & $3.01 \%$ \\
Indonesia & $33,434,000.00$ & & $38,302,000.00$ & \\
& $418,662.00$ & $0.83 \%$ & $752,654.00$ & $1.26 \%$ \\
Bank OCBC NISP & $50,141,559.00$ & & $59,834,397.00$ & \\
& $4,882.00$ & $0.24 \%$ & $3,651.00$ & $1.74 \%$ \\
Bank Windu Kentjana & $2,007,966.00$ & & 209.466 .00 & \\
International & & $\mathbf{1 . 3 7 \%}$ & & $\mathbf{2 . 0 0} \%$ \\
\hline Rata-Rata & & & &
\end{tabular}

Perhitungan Return On Equity pada tabel 5 menunjukan peningkatan pada ketiga perusahaan di atas yaitu Bank UOB Indonesia, Bank OCBC NISP, Bank Windu Kentjana International sebelum merger yaitu
$11,87 \%, 7.18 \%, 1.18 \%$ menjadi sesudah merger sebesar $12.53 \%, 11.42 \%$, dan $1.39 \%$. Hal ini membuktikan bahwa perusahaan yang melakukan merger akan meningkatkan rasio Return On Equity. 
Tabel 5. Return On Equity Perusahaan sebelum dan sesudah Merger (dalam jutaan rupiah)

\begin{tabular}{lrcrc}
\hline Perusahaan & Sebelum & \multicolumn{3}{c}{ Sesudah } \\
\hline PT Bank UOB & $723,000.00$ & $11.87 \%$ & $865,000.00$ & $12.53 \%$ \\
Indonesia & $6,090,000.00$ & & $6,906,000.00$ & \\
& $418,662.00$ & $7.18 \%$ & $752,654.00$ & $11.42 \%$ \\
Bank OCBC NISP & $5,830,743.00$ & & $6,590,379.00$ & \\
& $4,882.00$ & $1.18 \%$ & $3,651.00$ & $1.39 \%$ \\
Bank Windu Kentjana & $269,811.00$ & & $261,990.00$ & \\
International & & $\mathbf{6 . 9 5 \%}$ & & $\mathbf{8 . 4 5} \%$ \\
\hline Rata-Rata & & & & \\
\hline
\end{tabular}

Sumber : Data Primer yang diolah

Perhitungan Earning Per Share pada tabel 6 terlihat bahwa perusahaan Bank OCBC NISP cenderung tetap yaitu sebelum merger dan sesudah merger senilai 70.42 sedangkan pada Perusahaan Bank UOB Indonesia dan Bank Windu Kentjana International meningkat mulai dari sebelum merger sebesar 3.63 dan -996.33 menjadi sesudah merger 7.26 dan 27.45. Hal ini mengakibatkan meningkatnya pembagian laba yang dinikmati oleh pegang saham jika perusahaannya melakukan merger.

Tabel 6. Earning Per Share Perusahaan sebelum dan sesudah Merger (dalam jutaan rupiah)

\begin{tabular}{lrrrr}
\hline Perusahaan & \multicolumn{3}{c}{ Sebelum } & \multicolumn{3}{c}{ Sesudah } \\
\hline PT Bank UOB & $1,013,000.00$ & 3.63 & $1,154,000.00$ & 7.26 \\
Indonesia & $279,000.00$ & & $159,000.00$ & \\
& $418,662.00$ & 70.42 & $752,654.00$ & 70.42 \\
Bank OCBC NISP & $5,945.00$ & & $10,688.00$ & \\
& $(4,882.00)$ & $(996.33)$ & $3,651.00$ & 27.45 \\
Bank Windu Kentjana & 4.90 & & 133.00 & \\
International & & $\mathbf{- 3 0 7 . 4 2}$ & & $\mathbf{3 5 . 0 4}$ \\
\hline Rata-Rata & & & &
\end{tabular}

Dari data yang diperoleh pada tabel 7 terlihat bahwa Total Asset Turn Over perusahaan-perusahaan yang melakukan merger tidak berubah cenderung tetap dapat dilihat untuk perusahaan Bank UOB Indonesia dan Bank OCBC NISP sebelum dan sesudah merger yaitu 0.03 dan 0.01 sedangkan Bank Windu Kentjana International mengalami peningkatan dari sebelum merger yaitu 0.00 menjadi sesudah merger 0.02. Hal ini menunjukan bahwa Total Asset Turn Over (TATO) perusahaan yang melakukan merger cenderung tetap hanya mengalami perubahan tidak signifikan.

Tabel 7. Total Asset Turn Over Perusahaan sebelum dan sesudah Merger (dalam jutaan rupiah)

\begin{tabular}{lrrrr}
\hline Perusahaan & Sebelum & \multicolumn{3}{r}{ Sesudah } \\
\hline PT Bank UOB & $1,010,000.00$ & 0.03 & $1,172,000.00$ & 0.03 \\
Indonesia & $33,434,000.00$ & & $38,302,000.00$ & \\
& $563,177.00$ & 0.01 & $650,866.00$ & 0.01 \\
Bank OCBC NISP & $50,141,559.00$ & & $59,834,397.00$ & \\
& 399.00 & 0.00 & $4,822.00$ & 0.02 \\
Bank Windu Kentjana & $2,007,966.00$ & & 209.466 .00 & \\
International & & $\mathbf{0 . 0 1}$ & & $\mathbf{0 . 0 2}$ \\
\hline Rata-Rata & & & &
\end{tabular}


Pada tabel 8 terlihat bahwa Current Ratio pada Bank UOB Indonesia menunjukan peningkatan yaitu sebelum akuisisi $119,82 \%$ menjadi sesudah merger 120,21\% lain halnya dengan current ratio Bank OCBC NISP dan Bank Windu Kentjana International yang mengalami penurunan pada sebelum merger $109.58 \%$ dan $110.47 \%$, setelah merger menjadi $109.02 \%$ dan $107.31 \%$. Hal ini menunjukan bahwa perusahaan yang melakukan merger tidak likuid setelah melakukan merger. Sedangkan pada hasil perhitungan Debt Ratio Bank UOB Indonesia, Bank OCBC NISP dan Bank Windu Kentjana International sebelum merger sebesar $81.79 \%$, $88.37 \%$, dan $86.56 \%$ sesudah merger menjadi $81.97 \%$, 88.99\% dan $87.49 \%$. Hal ini menunjukan bahwa perusahaan yang melakukan merger memiliki kewajiban semakin tinggi setelah merger.

Tabel 8. Total Asset Turn Over Perusahaan sebelum dan sesudah Merger (dalam jutaan rupiah)

\begin{tabular}{lrrrr}
\hline Perusahaan & Sebelum & \multicolumn{3}{c}{ Sesudah } \\
\hline PT Bank UOB & $1,010,000.00$ & 0.03 & $1,172,000.00$ & 0.03 \\
Indonesia & $33,434,000.00$ & & $38,302,000.00$ & \\
& $563,177.00$ & 0.01 & $650,866.00$ & 0.01 \\
Bank OCBC NISP & $50,141,559.00$ & & $59,834,397.00$ & \\
& 399.00 & 0.00 & $4,822.00$ & 0.02 \\
Bank Windu Kentjana & $2,007,966.00$ & & 209.466 .00 & \\
International & & $\mathbf{0 . 0 1}$ & & $\mathbf{0 . 0 2}$ \\
\hline Rata-Rata & & & &
\end{tabular}

Dari tabel rekapitulasi dapat dilihat bahwa $R a$ sio Net Profit Margin (NPM), Return On Investment (ROI), Earning Per share (EPS), dan Total Asset Turn Over (TATO) pada perusahaan yang melakukan merger mengalami peningkatan, sesudah melakukan merger. Hal ini menunjukan sesuai dengan teori bahwa perusahaan yang melakukan merger akan meningkatkan ratio-ratio keuntungannya. Lain halnya dengan Return On Equity (ROE), Current Ratio (CR) dan Debt Ratio mengalami penurunan setelah melakukan merger. Hal ini menunjukan pada perusahaan yang melakukan merger akan meningkat kewajiban dibandingkan dengan aset yang di miliki. Hasil penelitian ini sejalan dengan teori efisi- ensi Menurut Dharmasetya dan Sulaimin (dalam Wangi, 2010), merger dapat meningkatkan efisiensi karena akan terbentuk sinergi, yang secara sederhana diartikan sebagai $2+2=5$, yaitu konsep dalam ilmu ekonomi yang mengatakan gabungan faktor-faktor yang komplementer akan menghasilkan keuntungan yang berlipat ganda. Sinergi tersebut dapat berupa sinergi manajemen, sinergi operasi, dan sinergi keuangan

Tabel 9. Rekapitulasi Kinerja Keuangan Perusahaan Sebelum dan sesudah Akuisisi

\begin{tabular}{ccccc}
\hline Variabel & Rata-Rata (Sebelum) & Rata-Rata (Sesudah) & Standar Deviasi & Naik / Turun \\
\hline NPM & $73.04 \%$ & $81.52 \%$ & $8.48 \%$ & Naik \\
ROI & $1.51 \%$ & $1.92 \%$ & $0.41 \%$ & Naik \\
ROE & $10.78 \%$ & $9.73 \%$ & $-1.05 \%$ & Turun \\
EPS & 80.96 & 94.90 & 13.94 & Naik \\
TATO & 0.02 & 0.02 & 0.00 & Naik \\
CR & $114.38 \%$ & $79 \%$ & $-35.25 \%$ & Turun \\
Debt Ratio & $86.10 \%$ & $363 \%$ & $276.78 \%$ & Turun \\
\hline
\end{tabular}

\section{Kesimpulan}

Berdasarkan data yang diteliti mengenai Net Profit Margin (NPM) perusahaan sebelum dan sesudah merger mengalami peningkatan sebesar $9.02 \%$. Ra- sio profitabilitas yang diukur dengan NPM menunjukkan perbedaan pada periode satu tahun sebelum dengan satu tahun sesudah merger, yang berarti perusahaan semakin efisien dalam memanfaatkan 
aktivanya untuk kegiatan operasional perusahaan dan kinerja manajemen semakin efektif dibanding sebelum merger. Berdasarkan data yang diteliti mengenai NPM perusahaan sebelum dan sesudah Akuisisi mengalami peningkatan sebesar $8.48 \%$ dapat. Rasio profitabilitas yang diukur dengan NPM menunjukkan perbedaan pada periode satu tahun sebelum dengan satu tahun sesudah akuisisi, yang berarti perusahaan semakin efisien dalam memanfaatkan aktivanya untuk kegiatan operasional perusahaan dan kinerja manajemen semakin efektif dibanding sebelum akuisisi.

Return on investment (ROI) pada penelitian ini menyimpulkan bahwa perusahaan yang melakukan merger mengalami peningkatan sebesar $0.64 \%$. Rasio profitabilitas yang diukur dengan ROI menunjukkan perbedaan pada periode satu tahun sebelum dengan satu tahun sesudah merger, yang berarti perusahaan semakin efisien dalam memanfaatkan assetnya untuk kegiatan operasional perusahaan dan kinerja manajemen semakin efektif dibanding sebelum merger. Return on investment (ROI) pada penelitian ini menyimpulkan bahwa perusahaan yang melakukan akuisisi mengalami peningkatan sebesar $0.41 \%$. Rasio profitabilitas yang diukur dengan ROI menunjukkan perbedaan pada periode satu tahun sebelum dengan satu tahun sesudah akuisisi yang berarti perusahaan semakin efisien dalam memanfaatkan assetnya untuk kegiatan operasional perusahaan dan kinerja manajemen semakin efektif dibanding sebelum akuisisi.

Berdasarkan penelitian yang lakukan mengenai Return on Equity (ROE) ialah terdapat peningkatan pada perusahaan yang melakukan merger yaitu sebesar $1.49 \%$. Rasio profitabilitas yang diukur dengan ROE menunjukkan perbedaan pada periode satu tahun sebelum dengan satu tahun sesudah merger yang berarti perusahaan semakin efisien dalam memanfaatkan modalnya untuk kegiatan operasional perusahaan dan kinerja manajemen semakin efektif dibanding sebelum merger. Berdasarkan penelitian yang lakukan mengenai ROE ialah terdapat penurunan pada perusahaan yang melakukan akuisisi sebesar $1.05 \%$. Rasio profitabilitas yang diukur dengan ROE menunjukkan perbedaan pada periode satu tahun sebelum dengan satu tahun sesudah akuisisi yang berarti perusahaan kurang efisien dalam memanfaatkan modalnya untuk kegiatan operasional perusahaan dan kinerja manajemen semakin efektif dibanding sebelum akuisisi.

Berdasarkan data yang diteliti mengenai Earning Per Share (EPS) pada perusahaan sebelum dan sesudah merger mengalami peningkatan sebesar $342.47 \%$. Rasio nilai pasar yang diukur dengan EPS menunjukkan perbedaan pada periode satu tahun sebelum dengan satu tahun sesudah merger, yang berarti setelah merger tingkat kepercayaan investor terhadap kinerja jangka panjang perusahaan semakin meningkat. Berdasarkan data yang diteliti mengenai EPS pada perusahaan sebelum dan sesudah akuisisi mengalami peningkatan sebesar $13.94 \%$. Rasio nilai pasar yang diukur dengan Earning Per Share (EPS) menunjukkan perbedaan pada periode satu tahun sebelum dengan satu tahun sesudah akuisisi, yang berarti setelah merger tingkat kepercayaan investor terhadap kinerja jangka panjang perusahaan semakin meningkat.

Total Assets Turn Over (TATO) pada penelitian ini menyimpulkan bahwa perusahaan yang melakukan merger mengalami kenaikan $0.01 \%$. Rasio manajemen aset mengukur seberapa efisien manajemen perusahaan mengelola aktivanya. Dengan merger maka perusahaan dapat meningkatkan efektifitas perusahaan sehingga aset yang dimiliki oleh perusahaan dapat digunakan secara efisien untuk meningkatkan penjualan (total assets turnover). Total Assets Turn Over (TATO) pada penelitian ini menyimpulkan bahwa perusahaan yang melakukan merger mengalami kenaikan kurang dari $0.01 \%$. Rasio manajemen aset mengukur seberapa efisien manajemen perusahaan mengelola aktivanya. Dengan merger maka perusahaan dapat meningkatkan efektifitas perusahaan sehingga aset yang dimiliki oleh perusahaan dapat digunakan secara efisien untuk meningkatkan penjualan (total assets turnover).

Berdasarkan penelitian yang lakukan mengenai Current Ratio (CR) ialah menyimpulkan bahwa perusahaan yang melakukan merger mengalami penurunan $1.11 \%$. Rasio likuiditas yang diukur dengan CR menunjukkan perbedaan pada periode satu tahun sebelum dengan satu tahun sesudah merger yang berarti kurang efisiensi perusahaan dalam menggunakan aktiva lancarnya untuk mengelola kewajiban lancar semakin meningkat setelah penggabungan badan usaha. Berdasarkan penelitian yang lakukan mengenai CR ialah menyimpulkan bahwa perusahaan yang melakukan akuisisi mengalami penurunan $35.25 \%$. Rasio likuiditas yang diukur dengan CR menunjukkan perbedaan pada periode satu tahun sebelum dengan satu tahun sesudah akuisisi yang berarti kurang efisiensi perusahaan dalam menggunakan aktiva lancarnya untuk mengelola kewajiban lancar semakin meningkat setelah penggabungan badan usaha. 
Berdasarkan penelitian yang lakukan mengenai Debt Ratio terdapat perusahaan yang melakukan merger cenderung meningkat, peningkatannya sebesar $0.58 \%$. Rasio manajemen hutang merupakan tingkat jumlah hutang terhadap seluruh kekayaan perusahaan. Jika terjadi sinergi atas dilakukannya merger maka secara umum kesertaan modal kurang baik sehingga tidak dapat meminimalisir penggunaan hutang dan tidak dapat mengurangi beban aset untuk menjamin hutang tersebut (debt ratio).'Berdasarkan penelitian yang lakukan mengenai Debt Ratio terdapat perusahaan yang melakukan akuisisi meningkat, peningkatannya sebesar $276.78 \%$. Rasio manajemen hutang merupakan tingkat jumlah hutang terhadap seluruh kekayaan perusahaan. Jika terjadi sinergi atas dilakukannya akuisisi maka secara umum kesertaan modal kurang baik sehingga tidak dapat meminimalisir penggunaan hutang dan tidak dapat mengurangi beban aset untuk menjamin hutang tersebut (debt ratio).

\section{Saran}

Dapat digambarkan bahwa perusahaan yang akan melakukan akuisisi sebaiknya harus lebih berhatihati dalam menggunakan modal sendirinya yaitu dengan mengurangi modal sendiri dan menambahkan modal dari pinjaman. selain itu, bahwa perusahaan yang akan melakukan akuisisi dan merger harus mengenal aktivas dan kewajiban lancarnya perusahaan sehingga bisa mengendalikan pengelo- laan aktivas lancar agar tidak berbanding lurus dengan kewajiban lancar. dengan kata lain, perusahaan yang akan melakukan akuisisi dan merger harus meningkatkan aktiva lancarnya atau mengurangi kewajiban lancarnya agar perusahaan yang ingin melakukan akuisisi atau merger dapat melunasi kewajiban lancarnya dengan aktiva lancarnya. Rasio likuiditas memberikan informasi yang sangat berguna bagi pengakuisisi ketika menilai perusahaan target, yaitu seberapa besar tingkat likuiditas pascamerger. Jika segera sesudah merger perusahaan memerlukan dana yang likuid, maka perusahaan akan relatif lebih aman jika memiliki rasio likuiditas yang tinggi. Dengan penggabungan usaha maka semestinya kemampuan perusahaan untuk memenuhi hutang jangka pendek (current ratio) akan meningkat.

Semakin besar perusahaan maka semakin besar pula kewajiban yang harus ditanggung oleh perusahaaan, dengan melakukan akuisisi atau merger perusahaaan akan menambah kewajiban dan masing-masing pengakuisi dan mergerial perusahaan. Walaupun akan menambahkan pula asset yang dimiliki. Dengan demikian, perusahaan yang akan melakukan merger atau akuisisi sebaiknya melihat aktiva dan kewajiban perusahaan yang dimiliki serta perusahaan yang akan diakuissi atau merger, sehingga perusahaan dapat mengelola aktivanya dengan baik dan kewajibannya dengan baik.

\section{Referensi}

Alao, R. O. (2010). Mergers and Acquisitions (M\&As) in the Nigerian Banking Industry: An Advocate of three Mega Banks. European Journal of Social Sciences. Vol. 15, No. 4, pp. 554-563.

Beams, Floyd A. dan Amir Abadi Yusuf (2000). Akuntansi Keuangan Lanjutan di Indonesia (Buku Satu). Jakarta: Salemba Empat.

Durga, Roa S., dan Kumar, R. P. (2013). Financial Performance Evaluation of Indian Commercial Banks During Before and After Mergers. Sumedha Journal Of Management. Vol. 2, No.1, pp. 117-129.

Dyaksa Widyaputra. (2006). "Analisis Perbandingan Kinerja Perusahaan \& Abnormal Return Saham Sebelum dan Sesudah Merger dan Akuisisi", Tesis Program Pasca Sarjana Magister Manajemen Universitas Diponegoro (tidak dipublikasikan), Semarang.

Hamid, Mudasetia, (1998). Merger dan Akuisisi, Latar Belakang dan Faktor-faktor yang Mempengaruhi, Kajian Bisnis. No. 13.

Hitt, M. A., (2002). Merger dan Akuisisi: Panduan Bagi Para Pemegang Saham Untuk Meraih Laba, Terjemahan, Cetakan Pertama, Jakarta: Erlangga.

Horne, J. C. V., \& John M. Wachowicz, J. (2004). Fundamentals of Financial Management. UK: Prentice Hall. 
Kurniawan, Herwin. (2015). Analisis Return On Asset (Roa) Beberapa Bank Pasca Merger Di Indonesia. Jurnal Ilmiah WIDYA. Vol. 3. No. 2, pp. 73-79.

Moin, Abdul. 2010. Merger, Akuisisi, dan Divestasi. Edisi Kedua. Yogyakarta: Ekonisia.

Monteiro, Mario Augusto Parente, Marcelle Colares Oliveira, Rosilene Marcon, dan Roberta Carvalho de Alencar. (2014). External Corporate Governance Mechanisms: Mergers And Acquisitions On The Brazilian Market. Revista de Gestão, Finanças e Contabilidade. Vol. 4, No. 2, pp. 4-19.

Munawir. 2001. Analisis Laporan Keuangan, Liberty: Yogyakarta

Nazir, Moh. 2005. Metode Penelitian. Cetakan Keenam. Bogor: Ghalia Indonesia.

Payamta dan Setiawan, 2004. Analisis Pengaruh Merger dan Akuisisi Terhadap Kinerja Perusahaan Publik di Indonesia, Jurnal Riset akuntansi Indonesia, Vol.7, No.3.

Sarah dan Maksum. (2009). Analisis Kinerja Keuangan Sebelum dan Sesudah Merger dan Akuisisi Pada Perusahaan Yang Terdapat di Bursa Efek Indonesia. Jurnal Fakultas Ekonomi Universitas Sumatra Utara.

Sugiyono. 2006. Metode Penelitian Bisnis, Cetakan Kesembilan, Bandung: CV Alvabeta

Utami, Elok Sri. (2013). Kinerja Finansial Perusahaan Yang Melakukan Akuisisi. Jurnal Akuntansi Universitas Jember.Vol. 11, No. 2, pp. 48-61.

Widjanarko, Hendro. (2004). Pengaruh Merger dan Akuisisi Terhadap Kinerja Perusahaan Manufaktur, Buletin Ekonomi, Vol.2, No.2.

Yu Yu. (2013). Review of mergers and acquisitions research in marketing. Innovative Marketing.Vol. 9, No. 1, pp. 27-35. 
$-40-$ 